\title{
CONTRATOS INTERNACIONAIS PRIVADOS: BRASIL VERSUS ESTADOS UNIDOS DA AMÉRICA
}

\section{PRIVATE INTERNATIONAL CONTRACTS BRAZIL VERSUS UNITED STATES OF AMERICA}

\begin{abstract}
Gabriela Maia de Souza ${ }^{1}$
e331139

RESUMO

https://doi.org/10.47820/recima21.v3i3.1139

O presente artigo objetiva discutir os contratos internacionais privados, dando-se ênfase à mitigação de danos no ordenamento jurídico dos Estados Unidos da América e na República Federativa do Brasil. Para tanto, aborda alguns aspectos inerentes aos contratos privados no direito estadunidense elucidando os critérios da razoabilidade, contratação substitutiva, gastos com a mitigação, violação antecipada do contrato e ônus da prova; e expõe alguns aspectos inerentes aos contratos privados no direito brasileiro esclarecendo sobre os lucros cessantes, nexo de causalidade, culpa concorrente e boa-fé objetiva. Visando cumprir o objetivo desse estudo, foi realizada uma pesquisa bibliográfica em doutrinas e na legislação vigente, fontes de pesquisa estas que orientaram a elucidação do tema proposto, permitindo concluir que o processo de aproximação jurídica promove o diálogo entre sistemas normativos em um esforço conjunto para o desenvolvimento do direito contratual de forma convergente. Como consequência desse processo, a evolução do direito contratual observa hoje um movimento cíclico em que diferentes sistemas interagem entre si e, nesse contexto, se desenvolve o princípio da mitigação de danos.
\end{abstract}

PALAVRAS-CHAVE: Contrato internacional privado. Direito comparado. Mitigação dos danos

\section{ABSTRACT}

This article aims to discuss private international contracts, emphasizing damage mitigation in the US and Brazilian legal system. Therefore, it addresses some aspects inherent to private contracts in US law, elucidating the criteria of reasonableness, substitute contracting, expenses with mitigation, early breach of contract and burden of proof; and exposes some aspects inherent to private contracts in Brazilian law, clarifying the loss of profits, causality, concurrent fault and objective good faith. Aiming to fulfill the objective of this research, a bibliographical research was carried out in doctrines and in the current legislation, these sources of research that guided the elucidation of the proposed theme, allowing to conclude that the process of legal approximation promotes the dialogue between normative systems in a joint effort for the development of contract law in a convergent way. As a result of this process, the evolution of contract law today observes a cyclical movement in which different systems interact with each other and, in this context, the principle of damage mitigation is developed.

KEYWORDS: Private international contract. Comparative law. Damage Mitigation

\section{INTRODUÇÃO}

Atualmente, vigora a noção de pluralismo jurídico, que sucedeu a concepção positivista do direito na evolução do pensamento jurídico. Essa transição foi impulsionada pelo fenômeno da globalização, que relativizou os conceitos de soberania e território. Reconhece-se a existência de

\footnotetext{
${ }^{1}$ Advogada inscrita na OAB e no International Bar Association (IBAZ) Especialista em Direito Público, Internacional, Tributário, Digital, Penal e Processual Penal, Marítimo, Médico e Hospitalar. LLM em Direito dos Contratos e Com MBAS Executivos nas Áreas de; Negócios Internacionais e Comércio Exterior, Controladoria e Finanças, Gerenciamento Executivo de Projetos, Petróleo e Gás, Gestão de Pessoas e Recursos Humanos, Marketing e Redes Sociais e Gestão Competitiva e Business Intelligence (BI). Pedagoga Especializada em Psicopedagogia, Neurociência e Comunicação em Ambientes Corporativos e Neuropsicopedagogia Institucional, Clínica e Hospitalar.
}

RECIMA21 - Ciências Exatas e da Terra, Sociais, da Saúde, Humanas e Engenharia/Tecnologia 


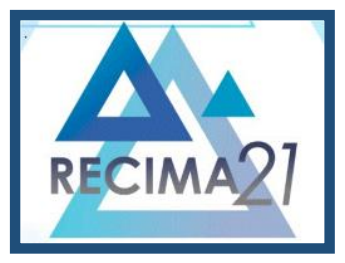

\section{RECIMA21 - REVISTA CIENTÍFICA MULTIDISCIPLINAR ISSN 2675-6218}

múltiplas ordens jurídicas, estatais e não estatais, que atuam umas sobre as outras, em diferentes níveis de intersecção.

A interação mútua entre sistemas é impulsionada pelo processo de aproximação jurídica do direito contratual, que surgiu como contramedida às disparidades entre os direitos nacionais, evidenciadas pela expansão do comércio internacional após o fim da $2^{\mathrm{a}}$ Guerra Mundial. Esse processo visa à criação de um direito contratual neutro, previsível e adaptado ao comércio internacional. Ao promover a convergência do direito contratual entre diferentes sistemas, a aproximação jurídica serve de fio condutor à evolução recíproca entre o direito estatal e o direito do comércio internacional.

Os métodos de aproximação jurídica podem ser agrupados em duas grandes categorias: (i) unificação, que se vale dos instrumentos vinculantes (hard law), criados no âmbito do direito internacional público; e (ii) harmonização, que se vale de instrumentos de instrumentos não vinculantes (soft law), criados no âmbito do direito do comércio internacional. A diferença entre os instrumentos desenvolvidos no seio de cada sistema jurídico está relacionada à sua densidade normativa. Os instrumentos vinculantes têm maior densidade normativa, porque, uma vez ratificados pelos Estados, têm aplicação compulsória. Os instrumentos não vinculantes têm menor densidade normativa, porque sua aplicação é voluntária e depende de seu poder de persuasão.

Os esforços de aproximação do direito contratual foram inicialmente concentrados na unificação do direito contratual. A principal vantagem da unificação jurídica está na força vinculante de seus instrumentos (hard law) e do consequente alto nível de aproximação jurídica proporcionados por eles. Contudo, o fato de as convenções imporem suas disposições aos Estados signatários torna o processo de formação, implementação e revisão desses instrumentos lento e formal.

O presente estudo objetiva discutir os contratos internacionais privados, dando-se ênfase à mitigação de danos no ordenamento jurídico dos Estados Unidos da América (EUA) e na República Federativa do Brasil.

Trata-se de uma pesquisa exploratória que visa apresentar uma pesquisa bibliográfica com vistas a conhecer as ideias e pensamentos de alguns autores que se dedicam ao estudo sobre os contratos internacionais privados.

Para o atingimento do objetivo proposto, este artigo encontra-se dividido em dois capítulos. $\mathrm{O}$ primeiro capítulo aborda alguns aspectos inerentes aos contratos privados no direito estadunidense elucidando os critérios da razoabilidade, contratação substitutiva, gastos com a mitigação, violação antecipada do contrato e ônus da prova. O segundo capítulo aborda alguns aspectos inerentes aos contratos privados no direito brasileiro esclarecendo sobre os lucros cessantes, nexo de causalidade, culpa concorrente e boa-fé objetiva.

\section{ALGUNS ASPECTOS INERENTES AOS CONTRATOS PRIVADOS NO DIREITO DOS ESTADOS UNIDOS DA AMÉRICA (EUA)}

No Direito Estadunidense, o princípio da mitigação dos danos também é concebido por meio da regra denominada avoidability. Trata-se de limitação de danos autônoma às demais aplicáveis à reparação de prejuízos. Essa regra impede que o credor seja indenizado por perdas que ele poderia 


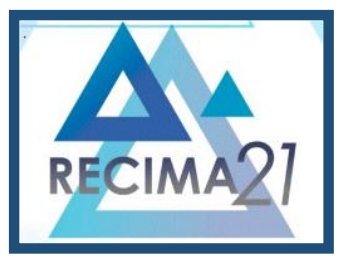

\section{RECIMA21 - REVISTA CIENTÍFICA MULTIDISCIPLINAR ISSN 2675-6218}

ter de forma razoável mitigado, embora lhe autorize a reparação dos custos ocorridos no emprego de esforços razoáveis para minimizar suas perdas.

O principal fundamento da regra no direito norte-americano é econômico. Goetz e Scott (1983) afirmam que a existência da regra exerce grande influência sobre a decisão do devedor entre (a) cumprir o contrato ou (b) inadimpli-lo e compensar o credor. Sem a avoidability, eventual indiferença do credor quanto à adoção de medidas mitigatórias poderia aumentar consideravelmente os custos do devedor na adoção da opção de descumprir o contrato. Os autores concluem que se trata de uma situação clássica de risco moral (moral hazard). Na ausência da mitigação de danos, o credor não teria incentivos econômicos para adotar medidas que beneficiassem o devedor. A mitigação de danos cria esses incentivos ao negar a indenização dos danos que poderiam ter sido razoavelmente evitados (KULESZA, 2015).

É comum a menção ao instituto sob o termo duty to mitigate losses na doutrina e jurisprudência norte-americanas. Contudo, assim como no direito inglês, nos EUA, há consenso sobre a inexistência de um dever propriamente dito do credor, porque este não responde perante o devedor ou terceiros caso não mitigue suas perdas. O credor é simplesmente impedido de ser indenizado por prejuízos que poderia ter evitado, caso tivesse empregado esforços razoáveis (FARNSWORTH, 1970).

\subsection{Critérios da razoabilidade}

No direito estadunidense, o duty to mitigate requer que o credor aja com vistas a mitigar os prejuízos que advêm do inadimplemento, sob pena de não ser indenizado pelos danos que poderiam ter sido evitados. Não se exige que o credor adote medidas para impedir que o inadimplemento ocorra, a mitigação de danos só incide após o descumprimento do contrato (LOPES, 2011).

Nos EUA, a mitigação é parametrizada pela noção de razoabilidade. A avaliação da razoabilidade da conduta do credor ante ao inadimplemento é feita atentando-se às circunstâncias específicas inerentes a cada caso concreto. $O$ direito norte-americano também usa o ordinary course of business como modelo de referência. Examinam-se as medidas mitigatórias disponíveis sob a perspectiva do credor no instante em que a quebra contratual ocorre (LOPES, 2011).

Caso aja razoavelmente, ainda que a medida mitigatória adotada não surta efeitos, o credor inadimplido terá direito à indenização de todos os prejuízos sofridos (Restatment [Second] on Contracts, § 350[2]). Nesse sentido, o credor não sofre sanção quando adota uma medida razoável, mas que se provou menos eficiente em comparação a outras também disponíveis à época do inadimplemento (GOETZ; SCOTT, 1983).

Embora a razoabilidade de cada medida mitigatória seja definida casuisticamente, o direito norte-americano fixou alguns parâmetros. Nesse sentido, não se exige que o credor inadimplido dispenda esforços contra riscos imprevisíveis ou que envolvam excessivos encargos ou humilhação (Restatment [Second] on Contracts, §350[1]). Do mesmo modo, o credor não deve (i) agir em detrimento de seus próprios interesses; (ii) prejudicar sua reputação comercial ou sua condição financeira; (iii) sacrificar direitos; ou (iv) aceitar uma proposta irrazoável do devedor para reduzir as consequências danosas da quebra contratual (BATES, 1992).

RECIMA21 - Ciências Exatas e da Terra, Sociais, da Saúde, Humanas e Engenharia/Tecnologia 


\section{RECIMA21 - REVISTA CIENTÍFICA MULTIDISCIPLINAR ISSN 2675-6218}

CONTRATOS INTERNACIONAIS PRIVADOS: BRASIL VERSUS ESTADOS UNIDOS DA AMÉRICA Gabriela Maia de Souza

\subsection{Contratação substitutiva}

A contratação substitutiva (substitutive transaction) também é medida mitigatória comumente reconhecida nos EUA. Essa medida tem especial aplicação nos contratos de compra e venda. No direito norte-americano, entende-se que o comprador (ou vendedor) inadimplido deve buscar a celebração de um contrato com terceiro no mercado para compra (ou venda) do bem objeto do contrato.

O direito norte-americano criou fórmulas para o cálculo da indenização do comprador ou vendedor inadimplido que refletem a regra da contratação substitutiva (market price formulas) (UCC, § $2-708[1]^{1}$ e $\S 2-713[1]^{2}$ ). Nos casos em que o credor efetua a compra ou venda de bem similar àquele objeto do contrato descumprido, sua indenização é quantificada segundo a diferença entre o preço contratual e o preço da contratação substitutiva (critério concreto).

Nos casos em que o credor inadimplido não realiza a contratação substitutiva, mas seria razoável fazê-lo, sua indenização é calculada com base na diferença entre o preço contratual e o preço de mercado do bem (critério abstrato). Essas fórmulas são baseadas nos prejuízos que a parte sofreria caso realizasse a contratação substitutiva. Ou seja, são aplicáveis quando a contratação substitutiva não é realizada pelo credor. Trata-se de um atalho para a quantificação de prejuízos do credor, que tem o bônus de não ser obrigado a comprovar o montante dos prejuízos sofridos e o ônus de ter sua indenização quantificada segundo uma ficção jurídica (KULESZA, 2015).

A aplicação das fórmulas de indenização ocorre apenas quando o credor inadimplido poderia ter razoavelmente contratado uma prestação substitutiva. Nos casos em que não era razoável fazê-lo (ainda que possível), a indenização do credor não é reduzida pelos danos que poderiam ter sido evitados. Na realidade, como visto, a razoabilidade é condição sine qua non para aplicação da avoidability no direito norte-americano (FARNSWORTH, 1970).

A análise da razoabilidade de determinada prestação alternativa disponível no mercado depende de uma diversidade de circunstâncias. A primeira delas reside na disponibilidade da prestação inadimplida no mercado. O mercado relevante a ser considerado na fórmula é aquele em que a contratação substitutiva teria razoavelmente ocorrido (FARNSWORTH, 1970).

Farnsworth (1970) cita a título de exemplificação um contrato de compra e venda em que um comprador realiza a compra de um bem em um determinado mercado e o revende em outro. Se há inadimplemento do vendedor, a fórmula de indenização deve considerar o preço do bem no mercado em que o comprador teria adquirido o bem e não no qual ele o revenderia. Do mesmo modo, se há descumprimento do comprador, o mercado de referência para o vendedor é aquele em que o vendedor teria vendido o bem ao comprador. Em outras palavras: a fórmula de mercado deve considerar os termos do contrato original.

\footnotetext{
1 Quando não há contratação substitutiva, a indenização do vendedor é calculada da seguinte forma: [indenização do vendedor] $=$ [preço de mercado do bem] - [preço contratual] + [despesas extras] - [custos evitados com o descumprimento do contrato].

2 Quando não há contratação substitutiva, a indenização do comprador é normalmente calculada da seguinte forma: [indenização do comprador] = [preço de mercado do bem] - [preço contratual] + [despesas extras] - [custos evitados com o descumprimento do contrato].
}

RECIMA21 - Ciências Exatas e da Terra, Sociais, da Saúde, Humanas e Engenharia/Tecnologia 


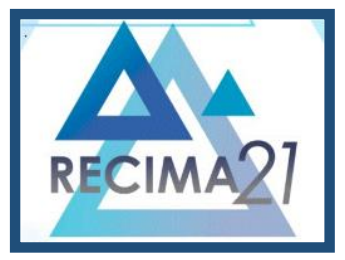

\section{RECIMA21 - REVISTA CIENTÍFICA MULTIDISCIPLINAR ISSN 2675-6218}

Não necessariamente o preço relevante no mercado para fins de cálculo da indenização será aquele praticado em contratos de prestação imediata. Nos casos em que o contrato de compra e venda descumprido era de cumprimento contínuo a longo prazo, o preço de mercado a ser utilizado como referência para a fórmula de indenização deve ser aquele de contratos de longo prazo (KULESZA, 2015).

Além disso, embora pareça razoável que o momento em que o preço do mercado deve ser apurado para aplicação na fórmula de indenização seja aquele em que a prestação inadimplida teria sido cumprida, entende-se que o correto seja apurar o preço de mercado quando a prestação substitutiva teria sido contratada, i.e., dentro de um lapso temporal razoável após o inadimplemento.

Caso o credor inadimplido realize a contratação substitutiva, sua indenização será calculada pela efetiva diferença entre o preço contratual e o preço do bem adquirido ou vendido no mercado (UCC, § 2-706[1]; § 2-712[2]). Se o vendedor efetuar a contratação substitutiva, não terá que comprovar que realizou a revenda pelo melhor preço de mercado. Exige-se apenas que comprove que agiu de boa-fé e que a contratação substitutiva foi comercialmente razoável (UCC, § 2-706[1]). O mesmo grau de exigência é aplicável ao comprador, que deve comprovar que realizou a compra substitutiva do bem de boa-fé e de acordo com padrões comercialmente razoáveis (UCC, § 2-712[1]).

Cumpridas essas exigências de razoabilidade, ainda que depois fique comprovado que 0 vendedor poderia ter negociado o bem por preço mais elevado ou que o comprador poderia ter pagado preço menor ao realizar a contratação substitutiva, a indenização do credor será calculada com base na efetiva diferença (actual loss) entre o contrato descumprido e a contratação substitutiva (FARNSWORTH, 1970).

Note-se que o direito estadunidense se afasta do direito inglês nesse ponto. Como visto, na Inglaterra, a indenização do credor é sempre calculada segundo o critério abstrato (diferença entre preço contratual e preço de mercado), ainda que o credor tenha realizado uma contratação substitutiva. Em contraste, nos EUA, nos casos em que o credor efetua a contratação substitutiva, a quantificação de suas perdas levará em consideração o critério concreto, i.e., a diferença entre o preço efetivamente praticado entre o credor e o terceiro e o contrato original (LOPES, 2011).

Espera-se que o credor proceda à contratação substitutiva em um período razoável de tempo após ter ciência de que o devedor não cumprirá sua obrigação ${ }^{3} 3$. Nos EUA, ao contrário do direito inglês, predomina o entendimento de que o credor não pode ignorar a notícia expressa do devedor de que não cumprirá o contrato (anticipatory repudiation) (UCC, § 2-723[1]). Por outro lado, eventual delonga em realizar a contratação substitutiva atribuível à legítima expectativa do credor de que o devedor cumpriria o contrato, é considerada razoável (BATES, 1992).

Nos demais casos, entende-se que o prejuízo decorrente da demora em contratar a prestação substitutiva (p.ex., no caso de um comprador, eventual aumento do preço do bem no mercado) deve ser suportado pelo credor inadimplido. Por outro lado, se há uma mudança favorável no mercado após a delonga do credor, o benefício também é considerado em prol do credor. Em resumo, nos EUA, o 


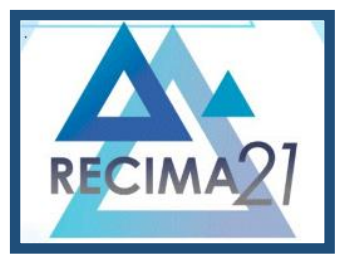

\section{RECIMA21 - REVISTA CIENTÍFICA MULTIDISCIPLINAR ISSN 2675-6218}

credor assume os riscos (e se beneficia dos eventuais ganhos) resultantes da contratação substitutiva extemporânea.

\subsection{Gastos com a mitigação}

No direito norte-americano, os gastos em que o credor incorre no emprego de medidas mitigatórias, ainda que infrutíferas (Restatement [Second] of Contracts, $§ 350$ [2]), devem ser reembolsados pelo devedor inadimplente (Restatement [Second] of Contracts, § 347). Essa regra é um corolário do princípio da mitigação de danos (UCC, §§ 2-710 e 2-715). Para serem indenizáveis, as despesas do credor devem ser razoáveis e decorrer da inexecução contratual. O ônus da prova do desembolso dessas despesas cabe ao credor.

\subsection{Quebra antecipada}

Nos EUA, nas hipóteses de quebra antecipada, o princípio da mitigação de danos exige que o credor reduza custos interrompendo sua contraprestação tão logo tenha motivos suficientes para acreditar que o devedor não cumprirá o contrato (Restatement [Second] of Contracts, § 350[1]). Essa situação ocorre especialmente quando há repúdio antecipado (anticipatory repudiation) do contrato pelo devedor (FARNSWORTH, 1970). Essa regra de redução de custos ficou consolidada no leading case Clark v. Marsiglia, julgado em 1845 pela Corte de Nova lorque.

O UCC possui um regramento específico para a hipótese de violação de contratos de compra e venda antecipadamente (UCC, § 2-610). No caso de inadimplemento do comprador, o UCC prevê que o vendedor pode optar por dar continuidade à produção das mercadorias apesar do repúdio do comprador, se "in the exercise of reasonable comercial judgment" entender que terá menos prejuízos na conclusão da produção em comparação à interrupção imediata. Se o vendedor agir de forma razoável, os custos ocorridos com a finalização da produção serão indenizáveis pelo comprador inadimplente. $\mathrm{Na}$ hipótese contrária (se entender que terá maiores prejuízos se der continuidade ao contrato), o vendedor tem a opção de interromper a produção e vender os bens como sucatas (UCC, $\S \S 2-703$ e 2-704[2]).

Nos casos de inadimplemento do vendedor, o comprador pode optar por realizar uma contratação substitutiva (UCC, § 2-712) ou ser indenizado pela diferença entre o preço do contrato e o preço de mercado (UCC, § 2-713). Como visto acima, o preço de mercado relevante é aquele do momento em que seria razoável que o credor tivesse realizado a contratação substitutiva. Essa é uma análise necessariamente casuística porque apurada segundo as circunstâncias fáticas de cada caso. Se o credor não contrata a prestação substitutiva no tempo devido, os riscos da flutuação do mercado são assumidos por ele (FARNSWORTH, 1970).

A jurisprudência norte-americana entende que o credor não deve adotar medidas mitigatórias enquanto o devedor não repudiar clara e definitivamente o contrato. Nesse sentido, só se exige que o credor interrompa sua contraprestação quando receber um sinal inequívoco de inadimplemento do devedor. Essa regra minora o risco de o devedor inadimplente alegar que o credor deveria ter agido antes para mitigar seus prejuízos (GOETZ; SCOTT, 1983).

RECIMA21 - Ciências Exatas e da Terra, Sociais, da Saúde, Humanas e Engenharia/Tecnologia 


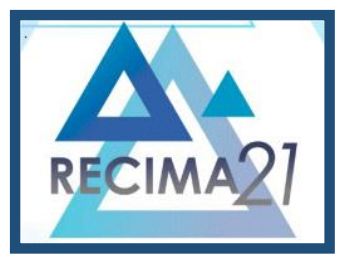

\section{RECIMA21 - REVISTA CIENTÍFICA MULTIDISCIPLINAR ISSN 2675-6218}

Um ponto de conflito entre o direito inglês e o estadunidense está na possibilidade de o credor não tomar medidas mitigatórias nos casos em que rejeita o repúdio antecipado do contrato (anticipatory repudiation) e busca a execução específica (specific performance) da obrigação do devedor, especialmente quando a prestação repudiada é de pagamento (TREITEL, 1991). No direito inglês, o credor pode recusar a anticipatory repudiation do devedor e dar seguimento à sua contraprestação, exigindo que seja paga a quantia devida pelo devedor no prazo acordado.

Nos EUA, prevalece o entendimento de que, sempre que a violação antecipada do devedor é explícita e expressa, o credor não tem opção: deve interromper sua contraprestação para reduzir seus custos mesmo que não queira aceitar a repudiation. Entende-se que, se o credor mantivesse sua prestação mesmo após a repudiation, aumentaria injustificadamente seus custos. Nesse sentido, as perdas suportadas pelo credor após o expresso repúdio do contrato não seriam indenizáveis porque poderiam ter sido evitados (TREITEL, 1991).

Treitel (1991) aponta que, embora esse raciocínio seja razoável em tese, há duas exceções que o contradizem. A primeira é que a avoidability aplica-se apenas à quantificação do valor devido ao credor quando há pedido de indenização (claim for damages) e não quando o devedor exige o pagamento do preço devido, i.e., a execução específica (specific performance) da obrigação de pagar inadimplida pelo devedor.

Nesse sentido, mesmo diante do repúdio claro e expresso do devedor, o credor poderia dar continuidade ao contrato e, na data acordada, exigir a contraprestação devida pelo devedor. Nessa hipótese de execução específica, o credor não estaria obrigado a mitigar seus prejuízos e, portanto, não haveria por que interromper sua prestação para diminuir seus custos.

A segunda objeção ao princípio de que o credor deve sempre interromper sua contraprestação diante do repúdio do devedor está no fato de que, em determinadas situações, dar continuidade ao contrato pode ser menos custoso e mais razoável do que interrompê-lo. O credor pode ter obrigações perante terceiros (por exemplo, em um contrato de empreitada, o empreiteiro pode ter obrigações com subcontratados) ou sua reputação pode ser abalada se o contrato for interrompido (TREITEL, 1991).

Nessa linha, Farnsworth (1970) cita o exemplo em que o comprador repudia a avença após o vendedor dar início à produção dos bens objeto do contrato. $O$ autor defende que o credor pode ser mais capaz de evitar perdas continuando a fabricação e vendendo os produtos acabados do que cessando a fabricação e tentando salvar o trabalho em andamento.

Vê-se, portanto, que a regra do direito norte-americano de que deve o credor interromper sua contraprestação com vistas a evitar custos desnecessários quando o devedor repudia o contrato antecipadamente e busca a execução específica da obrigação do devedor também não é isenta de dúvidas.

\section{5 Ônus da prova}

No direito estadunidense, segundo Bates (1992), o ônus de mostrar que a parte que sofreu a lesão poderia ter, mas não adotou, as medidas adequadas geralmente recaem sobre a parte em violação. Nesse sentido, cabe ao devedor demonstrar quais medidas poderiam ter sido tomadas pelo

RECIMA21 - Ciências Exatas e da Terra, Sociais, da Saúde, Humanas e Engenharia/Tecnologia 


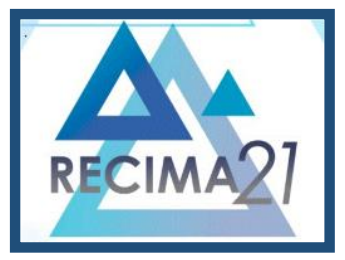

\section{RECIMA21 - REVISTA CIENTÍFICA MULTIDISCIPLINAR ISSN 2675-6218}

credor e o montante dos prejuízos que teriam sido evitados caso o credor tivesse adotado as medidas indicadas pelo devedor. Dada a dificuldade natural de o devedor ter informações a respeito das medidas mitigatórias que poderiam ter sido adotadas pelo credor, o discovery, mecanismo de busca de documentos muito utilizado no direito norte-americano, pode ser útil a fim de que o devedor pudesse obter provas do credor a esse respeito.

\section{ALGUNS ASPECTOS INERENTES AOS CONTRATOS PRIVADOS NO DIREITO BRASILEIRO}

Este capítulo é direcionado à análise dos contratos privados dando-se ênfase à internalização do princípio da mitigação de danos no ordenamento jurídico brasileiro. Ao contrário de outros países da América Latina (como a Bolívia e o Peru), o Brasil não possui uma regra expressa que preveja a mitigação de danos como limite à indenização do credor inadimplido. Contudo, a doutrina e jurisprudência brasileiras têm utilizado os instrumentos de aproximação jurídica (em especial, a CISG) para identificar o instituto no Código Civil brasileiro (CCbr.)

Atualmente, o princípio da mitigação de danos vivencia processo indiscutível de internalização no Brasil. Há diversos julgados que se fundamentam no instituto, ainda que de forma indireta, para reduzir o montante indenizatório.O estudo do direito brasileiro demonstra claramente a relevância dos instrumentos de aproximação do direito contratual para o desenvolvimento do princípio da mitigação de danos. Isso porque a CISG tem sido a principal responsável pela introdução do instituto no regime brasileiro de reparação de danos.

No caso brasileiro, a CISG, instrumento vinculante de unificação jurídica (hard law), adquire natureza de soft law, porque atua como fonte de inspiração para a introdução do princípio da mitigação de danos no sistema jurídico e não como norma de direito material aplicável. De fato, a CISG tem exercido uma influência branda sobre o direito brasileiro, semelhante ao processo voluntário de internalização dos instrumentos de harmonização jurídica (guias legislativos, restatements, etc.).

Três fatores comprovam que a convenção tem servido de fonte de inspiração ao direito brasileiro. Em primeiro lugar, a jurisprudência brasileira tem se utilizado da CISG para recepcionar o princípio da mitigação de danos no ordenamento jurídico desde muito antes de o Brasil ter aderido ao tratado e, portanto, antes de a CISG ter sido formalmente internalizada ao direito brasileiro. $\mathrm{O}$ uso de convenções não ratificadas como fonte de inspiração ao direito doméstico é expressamente reconhecido por Basso. Nas palavras da autora: "[e]nquanto o tratado ou convenção permanecer sem aprovação e ratificação internas, podemos usá-los como fonte material ou fonte de inspiração no caso concreto" (BASSO, 2020, p. 62).

Em segundo lugar, ainda que a CISG já estivesse em vigor, o fato é que os tribunais brasileiros têm feito menção ao tratado para conceber a mitigação de danos em casos de natureza estritamente doméstica (sem nenhum elemento de conexão estrangeiro), i.e., fora do escopo material de aplicação convenção (NALIN; SIRENA, 2012).

Em terceiro lugar, a primeira e mais importante manifestação do princípio da mitigação de danos no direito brasileiro encontra-se no enunciado 169, aprovado pelo Conselho da Justiça Federal

RECIMA21 - Ciências Exatas e da Terra, Sociais, da Saúde, Humanas e Engenharia/Tecnologia 


\section{RECIMA21 - REVISTA CIENTÍFICA MULTIDISCIPLINAR ISSN 2675-6218}

CONTRATOS INTERNACIONAIS PRIVADOS: BRASIL VERSUS ESTADOS UNIDOS DA AMÉRICA Gabriela Maia de Souza

na III Jornada de Direito Civil. O enunciado prevê que "o princípio da boa-fé objetiva deve levar o credor a evitar o agravamento do próprio prejuízo"4. Trata-se de uma fonte doutrinária de interpretação do art. 422 do CPC brasileiro, que prescreve a aplicação da boa-fé objetiva aos contratos domésticos. Segundo Fradera, autora do enunciado 169, a inspiração para redigi-lo surgiu "precisamente da leitura [do] artigo 77 da CISG"5.

Os direitos nacionais têm exercido pouca ou nenhuma influência no desenvolvimento da mitigação de danos no direito brasileiro. É antes a CISG (na qualidade de instrumento de soft law) que serve de fonte de inspiração para esse processo.

Apesar dessa aplicação ampla na jurisprudência brasileira, a recepção do instituto no Brasil não se encontra isenta de divergências. Nos próximos parágrafos analisam-se os fundamentos jurídicos frequentemente invocados pela doutrina e jurisprudência para recepção do princípio no Brasil. Antes de mais, esclareça-se que, no direito brasileiro, o estudo da indenização perpassa obrigatoriamente as disposições referentes à responsabilidade civil contratual e aquiliana.

No Brasil, vigora o princípio do ressarcimento integral (MARTINS-COSTA, 2009). Contudo, o sistema impõe algumas limitações à reparação de danos. A doutrina e jurisprudência brasileiras procuram extrair a mitigação de danos dessas limitações, em especial ao regime aplicável aos lucros cessantes (CCbr., art. 402), da noção de nexo causal (CCbr., art. 403) e da culpa concorrente (CCbr., art. 945).

\subsubsection{Lucros cessantes}

Invoca-se o instituto dos lucros cessantes com frequência pela jurisprudência para justificar a exclusão da responsabilidade do devedor inadimplente pelos prejuízos que deveriam ter sido evitados pelo credor. No entanto, a regra aplicável aos lucros cessantes não apresenta justificativa para todos os aspectos da mitigação de danos.

O CCbr. atual manteve a disposição prevista no diploma anterior segundo a qual o ressarcimento compreende tanto o dano emergente quanto aquele que o credor, de forma razoável, deixou de lucrar (CCbr. 1916, art. 1059; CCbr. 2002, art. 402). No que pertine à indenização dos lucros cessantes, acredita-se que a lei fixou um critério de "probabilidade objetiva resultante do desenvolvimento normal dos acontecimentos"6. Não se exige que o credor inadimplido comprove a

\footnotetext{
4 Enunciados aprovados pelo Conselho da Justiça Federal na III Jornada de Direito Civil. Disponíveis em: daleth.cjf.jus.br/revista/enunciados/IIIJornada.pdf. Acesso em: 17 Julho 2021.

${ }^{5}$ Razões do enunciado n. 169. Disponível em: flaviotartuce.adv.br/index2.php?sec=artigos\&tota Page=2. Acesso em: 17 julho 2021.

${ }^{6}$ BRASIL. STJ, REsp n. 846.455, Rel. Min. Castro Filho, j. 10.3.2009: "Correspondem os lucros cessantes a tudo aquilo que o lesado razoavelmente deixou de lucrar, ficando condicionado, portanto, a uma probabilidade objetiva resultante do desenvolvimento normal dos acontecimentos. A condenação a esse título pressupõe a existência de previsão objetiva de ganhos na data do inadimplemento da obrigação pelo devedor. No caso, os lucros alegados decorrem de previsões baseadas em suposta rentabilidade de uma atividade empresarial que nem mesmo se iniciou. Assim sendo, não se pode deferir reparação por lucros cessantes se estes, em casos como o dos autos, configuram-se como dano hipotético, sem suporte na realidade em exame, da qual não se pode ter a previsão razoável e objetiva de lucro, aferível a partir de parâmetro anterior e concreto capaz de configurar a potencialidade de lucro".
}

RECIMA21 - Ciências Exatas e da Terra, Sociais, da Saúde, Humanas e Engenharia/Tecnologia 


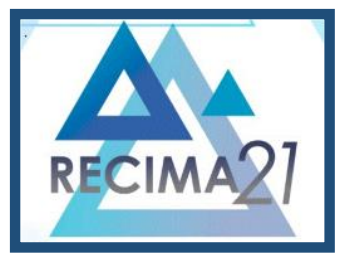

\section{RECIMA21 - REVISTA CIENTÍFICA MULTIDISCIPLINAR ISSN 2675-6218}

certeza do ganho perdido, mas a simples possibilidade de lucro também não é passível de indenização (TEPEDINO; SCHREIBER, 2008).

A conduta do credor após a quebra do contrato também é levada em consideração na análise do desenvolvimento normal dos acontecimentos após a inexecução do contrato. Caso o credor inadimplido deixe injustificadamente de tomar medidas que reduziriam a perda de seu lucro, este prejuízo não se inclui no montante indenizável, por referir-se a quantia que "irrazoavelmente se deixou de lucrar" (DIAS, 2011, p. 102).

Embora o CCbr. impeça a indenização dos lucros cessantes que a parte deixou de lucrar de forma irrazoável, o instituto dos lucros cessantes não é fundamento jurídico apropriado para a internalização da mitigação de danos no direito brasileiro. A principal razão para tanto está no fato de que o princípio da mitigação de danos impede a indenização do credor por todo prejuízo evitável (sobretudo os danos emergentes) e não apenas os lucros cessantes. Ademais, não é possível extrair do art. 402 do CCbr. regra que exija do credor a adoção de medidas para reduzir seu prejuízo.

\subsubsection{Nexo causal}

O CCbr. atual também reproduziu a disposição relativa ao caráter imediato e direto do dano indenizável prevista no código anterior (CCbr. 1916, art. 1.060; CCbr. 2002, art. 403). Assim, para ser indenizável pelo devedor o prejuízo deve ser efeito imediato e direto da inexecução contratual. Atribuise a essa expressão o necessário nexo de causalidade existente entre o descumprimento da obrigação e o dano.

O vínculo causal entre o dano e o inadimplemento depende da inexistência de um novo evento que quebre o referido vínculo e estabeleça um nexo de causalidade mais próximo com o dano. Nesse sentido, "é indenizável todo o dano que se filia a uma causa, ainda que remota, desde que ela Ihe seja causa necessária, por não existir outra que explique o mesmo dano" (CRUZ, 2005, p. 103).

Com base no nexo causal, há quem entenda possível afirmar que os danos desencadeados pelo descumprimento do contrato, mas que o credor poderia ter mitigado, não são passíveis de indenização, por referir-se a danos indiretos. Nessa linha, sustenta-se que os danos decorrentes da inércia do credor diante do inadimplemento não devem ser indenizados pelo devedor (ALVIM, 1972).

Em síntese, a causalidade não pode ser usada como fundamento ao princípio da mitigação de danos no direito brasileiro, porque não encontra justificativa para as hipóteses em que o credor não contribui ativamente para a ampliação das consequências danosas do inadimplemento.

\subsubsection{Culpa concorrente}

Parte da doutrina brasileira também concebe o princípio da mitigação de danos sob a perspectiva da culpa concorrente. Segundo o CCbr. (art. 945), a indenização dos prejuízos causados à vítima é fixada levando-se em consideração "a gravidade de sua culpa" em comparação à culpa do agente. A conduta da vítima é causa concorrente do dano quando ela e ato ilícito são condições necessárias para a produção do dano, daí o termo culpa concorrente (DIREITO, 2004). A culpa 


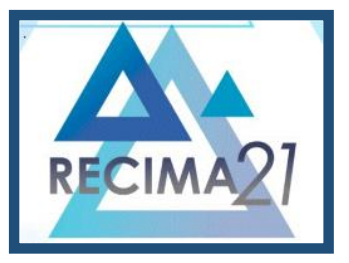

\section{RECIMA21 - REVISTA CIENTÍFICA MULTIDISCIPLINAR ISSN 2675-6218}

concorrente do credor ao inadimplemento é elemento atenuante da responsabilidade civil, ao passo que a culpa exclusiva do credor inadimplido exclui a responsabilidade do devedor.

Dias (2011) afirma que a culpa concorrente seria a via utilizada por países da família romanogermânica para resolver as situações em que vítima de um dano não adota medidas para minorá-los. No Brasil, ainda na vigência do CCbr. de 1916, a culpa da vítima era invocada para excluir a responsabilidade do devedor quanto aos danos que não foram evitados pelo credor. Entendia-se que a culpa do credor dava causa ao dano evitável. Nesse sentido, Pontes de Miranda (1983, p. 200) afirmava que a culpa da vítima decorreria "de ter o ofendido contribuído para a concorrência do dano [...] ou de ter concorrido para que o dano continuasse (crescimento no tempo) ou se fizesse maior (crescimento objetivo)".

$\mathrm{Na}$ vigência do CCbr. atual, a noção de culpa concorrente tem sido invocada pela jurisprudência brasileira para excluir do montante indenizatório os danos que poderiam ter sido evitados pela vítima, em casos de responsabilidade civil extracontratual. Discorda-se desse raciocínio. Em primeiro lugar, o art. 945 do CCbr. Menciona expressamente a concorrência da vítima ao "evento danoso", i.e., à conduta da vítima que contribui culposamente para o ato ilícito, mas não para o agravamento de suas consequências lesivas. Logo, não há como extrair o princípio da mitigação de danos da noção de culpa concorrente (LOPES, 2011). No campo da responsabilidade contratual, a distinção entre culpa concorrente e mitigação de danos é ainda mais evidente porque os institutos atuam em momentos diferentes da relação contratual.

De todo modo, ainda que se admitisse que o princípio da mitigação de danos pudesse encontrar aplicação no direito brasileiro pela via da culpa concorrente, alcança-se o mesmo impasse ressaltado nos itens anteriores: a ausência de norma que exija do credor a mitigação de seu próprio prejuízo. Isso porque o art. 945 do CCbr. sanciona a contribuição culposa da vítima ao evento danoso. A noção de culpa deriva da ilicitude: o indivíduo age culposamente quando sua conduta viola determinada norma jurídica (CORDEIRO, 2010). Dessa forma, o recurso ao instituto da culpa concorrente não é suficiente per se para recepcionar a mitigação de danos no Brasil. É preciso que uma norma imponha ao credor o ônus de mitigar suas perdas para que seu comportamento possa ser considerado culposo.

\subsection{Boa-fé objetiva}

$\mathrm{Na}$ opinião da doutrina majoritária, o fundamento jurídico da mitigação de danos no direito brasileiro encontra-se na cláusula geral da boa-fé objetiva (CCbr., art. 422). Na grande maioria dos precedentes brasileiros em que se sanciona o credor inadimplido por não empregar esforços para reduzir seu prejuízo, há menção à boa-fé objetiva (LOPES, 2011).

Indicativo relevante do vínculo estreito instituído entre o princípio da mitigação de danos e a boa-fé objetiva na ordem jurídica brasileira reside no acima mencionado enunciado 169 , que prevê que "o princípio da boa-fé objetiva deve levar o credor a evitar o agravamento do próprio prejuízo". A 


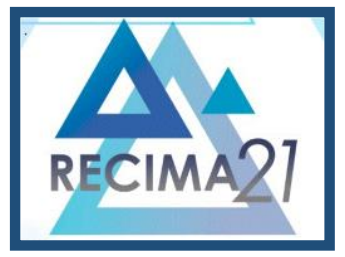

\section{RECIMA21 - REVISTA CIENTÍFICA MULTIDISCIPLINAR ISSN 2675-6218}

jurisprudência seguiu a tendência da doutrina e tem invocado o princípio da mitigação como corolário da boa-fé objetiva ${ }^{7}$.

O ímpeto de fundar o princípio da mitigação de danos na boa-fé objetiva não é inovador no sistema romano-germânico. Embora haja uma regra expressa que preveja a mitigação de danos no direito alemão (BGB, § 254[2]) e no direito italiano (CCit., 1227[2]), a doutrina e a jurisprudência desses sistemas encontraram na boa- fé o fundamento jurídico do princípio da mitigação de danos.

A principal inspiração para recepcionar o princípio da mitigação de danos no direito brasileiro está na CISG. Acredita-se que o princípio da mitigação de danos também se fundamenta na boa-fé objetiva no âmbito da convenção. O papel exercido pela CISG nesse contexto é revelar aos formantes do direito brasileiro que o princípio da mitigação de danos pode ser extraído da cláusula geral da boafé objetiva, amplamente reconhecida no Brasil (KULESZA, 2015).

Reconhecido que é possível fundamentar a mitigação de danos na boa-fé objetiva no direito brasileiro, resta saber qual a natureza jurídica da regra daí extraída. Nos próximos tópicos analisam-se os principais institutos invocados pela doutrina favorável à recepção do princípio da mitigação de danos por meio da boa- fé: (i) exercício tardio do direito (supressio); (ii) abuso do direito; (iii) dever acessório; e (iv) ônus do credor inadimplido. Conforme exposto a seguir, entende-se que a mitigação de danos tem natureza de ônus no direito brasileiro.

\section{$2.5 \quad$ Exercício tardio do direito}

O instituto do exercício tardio do direito é invocado com frequência pela jurisprudência para justificar a aplicação das consequências jurídicas da mitigação de danos. Essa figura jurídica aplicarse-ia à situação em que o credor inadimplido demora a pleitear a indenização do devedor. Nesse ínterim, o montante indenizatório aumenta em razão da incidência de juros moratórios e correção monetária (CCbr., art. 389, 402 e 404). Antes do prazo prescricional, o credor vem a juízo pleitear o ressarcimento de danos e os tribunais o sancionam pela inércia excessiva, reduzindo o montante indenizável, com base na mitigação de danos (DIAS, 2011).

A jurisprudência brasileira tem lançado mão do princípio da mitigação para reduzir o montante indenizatório perseguido pelo credor inadimplido nessas hipóteses ${ }^{8}$.

\footnotetext{
${ }^{7}$ A título de exemplo, v. BRASIL. TJSP, Apel. n. 1036109-0/8, Rel. Des. Rosa Maria de Andrade Nery, j. 27.6.2007: "Prestação de serviços. rescisão contratual. Análise de caso feita à luz do princípio da boa-fé objetiva e do princípio do dever de mitigar a própria perda. Inteligência do art.77 da Convenção de Viena de 1980"; BRASIL STJ, Habeas Corpus n. 137549, Rel. Min. Maria Thereza de Assis Moura, j. 07.02.2013: "O princípio da boa-fé objetiva ecoa por todo o ordenamento jurídico, não se esgotando no campo do Direito Privado, no qual, originariamente deita raízes. Dentre os seus subprincípios, destaca-se o duty to mitigate the loss".

8 A título de exemplo, BRASIL. TJRS, Apel. 70019328889, Rel. Des. José Francisco Pellegrini, j. 13.05.2009: "[P]arece-nos, diante do quadro posto, que a inação da parte credora é demasiada, e veio a agravar o prejuízo do devedor e - em tese, e aparentemente - o seu próprio dano. Pode-se cogitar que o credor haveria de, anteriormente a tão longa inércia (cerca de 15 anos), tomar as medidas judiciais cabíveis, e não meramente ter deixado o quadro fático dado. Em o fazendo, exsurge uma conduta indevida do credor que não providencia no mitigar do seu próprio prejuízo. Ou seja, a espera alongada do credor faz devida a remessa ao dever de mitigar o prejuízo, ou duty do mitigate the loss; entende-se que, como obrigação moral (obrigação em sentido lato), como inconbance (ônus para consigo próprio), ou como noção derivada da boa-fé, i.e., relativamente ao venire contra factum proprium, o credor adotou comportamento faltoso, conduta abusiva, a qual não se aceita, e que deve ser RECIMA21 - Ciências Exatas e da Terra, Sociais, da Saúde, Humanas e Engenharia/Tecnologia
} 


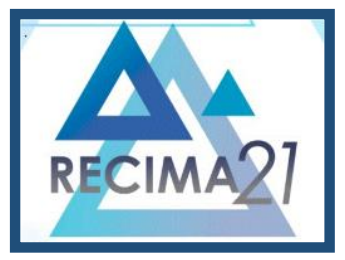

\section{RECIMA21 - REVISTA CIENTÍFICA MULTIDISCIPLINAR ISSN 2675-6218}

As possibilidades de aplicação da mitigação de danos com fundamento no exercício tardio podem ser segmentadas em dois grupos. No primeiro, incluem-se apenas os casos em que o montante indenizável é acrescido pela incidência dos juros de mora a partir do inadimplemento da obrigação. No segundo grupo, inserem- se os casos em que, embora também tenham incidido juros moratórios, o agravamento da obrigação de indenizar se deve essencialmente ao "inadimplemento reiterado das prestações pelo devedor" (DIAS, 2011, p. 127).

Com relação ao primeiro grupo de casos, entende-se que a aplicação do princípio da mitigação de danos seria desnecessária para excluir os prejuízos passíveis de ser evitados do montante indenizatório, diante da regra prevista no art. 405 do CCbr.: "contam-se os juros de mora desde a citação inicial" (BRASIL, 2002).

No entanto, esse entendimento não se aplica às obrigações positivas e líquidas, porque nesses casos o descumprimento da obrigação no termo constitui o devedor em mora de pleno direito, i.e., sem necessidade de interpelação (CCbr., art. 397). Trata-se dos casos em que há mora ex re. Prevalece o entendimento de que: '[...] os juros de mora começam a correr no momento em que o devedor se vê constituído em mora. Nas obrigações positivas e líquidas, com termo fixo, o não pagamento no vencimento estipulado constitui automaticamente em mora devedor' (TEPEDINO; SCHREIBER, 2008, p. 380).

Essa posição funda-se na ideia de que não se pode subverter a finalidade dos juros moratórios, "devidos como pena imposta ao devedor inadimplente, em regra o que demora a prestar" (MARTINSCOSTA, 2009, p. 371). O devedor que não presta a obrigação positiva e líquida no prazo avençado deve arcar com os juros, na medida em que "já está em mora e conhece sua obrigação de saldar o prejuízo" (PELUSO, 2007, p. 295). Por outro lado, a regra prevista no art. 405 do CCbr. encontra aplicação nos casos em que a obrigação inadimplida é ilíquida, porquanto "não se pode cobrar o ônus da mora de quem ignora o débito" (TEPEDINO; SCHREIBER, 2008, p. 733).

Nessa esteira, entende-se ser necessária a invocação do princípio da mitigação de danos caso o julgador pretenda reduzir o montante indenizatório pleiteado pelo credor, nos casos em que o inadimplemento recai sobre obrigação positiva e líquida, incidindo juros moratórios sobre a dívida desde a data do inadimplemento. Dito de outra forma, se o credor permanecer inerte após o inadimplemento do devedor de uma obrigação positiva e líquida, porém mover a demanda indenizatória antes do prazo prescricional, o juiz só poderá reduzir o montante indenizatório (p. ex., por meio da exclusão dos juros moratórios incidentes) caso entenda que o credor poderia ter razoavelmente mitigado suas perdas ajuizando a ação em momento prévio - hipótese tida por problemática na doutrina (LOPES, 2011).

De todo modo, a questão remanescente é saber qual seria o fundamento jurídico no direito brasileiro que permitiria ao juiz reduzir a indenização do credor com fundamento no princípio da mitigação de danos. Com relação ao segundo grupo de casos, entende-se que a mitigação de danos não seria necessária porque a supressão do direito do credor por exercício tardio de um direito

sopesada aos efeitos de analisar, aqui, o direito do autor, no que tange à extensão do crédito objeto do procedimento em liça".

RECIMA21 - Ciências Exatas e da Terra, Sociais, da Saúde, Humanas e Engenharia/Tecnologia 


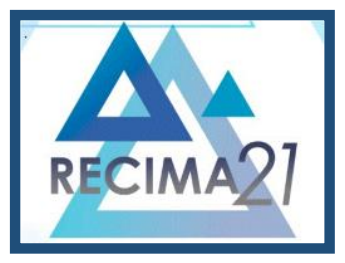

\section{RECIMA21 - REVISTA CIENTÍFICA MULTIDISCIPLINAR ISSN 2675-6218}

CONTRATOS INTERNACIONAIS PRIVADOS: BRASIL VERSUS ESTADOS UNIDOS DA AMÉRICA Gabriela Maia de Souza

encontraria resposta no instituto da supressio. Cordeiro (2010, p. 323) explica que "a supressio é, no fundo, uma forma de tutela da confiança do beneficiário, perante a inacção do titular do direito". O credor inadimplido teria seu direito de ressarcimento cerceado em razão de sua prolongada omissão, apta a gerar no devedor a legítima expectativa de que a cobrança não será mais exercida. Nos casos em que a supressio tem aplicação, figura-se de todo desnecessária e inadequada a invocação do princípio da mitigação de danos para afastar o direito do credor a ser indenizado, uma vez que o ordenamento brasileiro tem resposta própria a essa situação jurídica. Porém, na maioria dos casos em que os tribunais brasileiros aplicam a mitigação de danos, a supressio não deve ser aplicada, pois the falta premissa insuperável: a legítima confiança do devedor.

Nesse cenário, volta-se à situação de impasse ressaltada nos itens anteriores: não existe norma expressa no ordenamento brasileiro que imponha ao credor a mitigação de seu próprio prejuízo. Nota-se que o credor poderia simplesmente deixar seu crédito prescrever (CCbr., art. 206) ou mesmo remir a dívida (CCbr., art. 385). No entanto, a recepção do princípio da mitigação de danos ainda encontra alguma resistência na jurisprudência pátria, sobretudo em razão da ausência de uma norma expressa que exija do credor o emprego de medidas para conter seus prejuízos.

\subsection{Abuso do direito}

Outro instituto comumente aventado para a recepção da mitigação de danos reside na proibição do abuso do direito (CCbr., art. 187). Levando em consideração que o credor inadimplido tem direito a ser indenizado pela violação contratual (CCbr, arts. 389 e 475), aventa-se a possibilidade de se considerar abusivo o exercício pelo credor de seu direito à reparação com relação aos danos que ele próprio poderia ter evitado (LOPES, 2011).

Aqui, vale mencionar um dos acórdãos do TJSP que se posicionou nesse sentido. In casu, a concessionária que tinha a responsabilidade de fornecer água a determinado imóvel deu continuidade ao abastecimento, apesar de o locatário, responsável pelo pagamento das respectivas despesas, estar inadimplente. Nos termos do acórdão, "a concessionária de serviço essencial demorou quase dez anos para exigir a satisfação da dívida, utilizando-se da prerrogativa de interromper o abastecimento de água quando o imóvel já estava locado para terceiro"9.

A doutrina do abuso do direito divide-se em duas correntes: subjetiva e objetiva. A concepção subjetiva concentra-se no objetivo perseguido pelo agente ao exercer seu direito. Nessa hipótese, para que o abuso do direito reste configurado é importante que esteja presente o animus nocendi, i.e., a intenção de prejudicar (COSTA, 2006). "Abusa, pois, de seu direito o titular que dele se utiliza levando um malefício a outrem, inspirado na intenção de fazer o mal, e sem proveito próprio" (PEREIRA, 2020, p. 673).

Lopes (2011) defende ser difícil fundar a mitigação de danos nessa concepção subjetiva do abuso do direito, salvo raríssimas exceções em que o credor exerceria seu direito à indenização exclusivamente com o objetivo de lesar o devedor. Compartilha-se essa opinião. A vertente objetiva do 


\section{RECIMA21 - REVISTA CIENTÍFICA MULTIDISCIPLINAR ISSN 2675-6218}

CONTRATOS INTERNACIONAIS PRIVADOS: BRASIL VERSUS ESTADOS UNIDOS DA AMÉRICA Gabriela Maia de Souza

abuso de direito refere-se à averiguação da conduta do agente sob uma perspectiva racional, à luz dos dados de fato, e não da intenção do agente quando do exercício do direito. O entendimento da doutrina majoritária é que o art. 187 do CCbr. positivou a concepção objetiva do abuso do direito. Dito dispositivo legal prevê três hipóteses de exercício irregular do direito na medida em que viole: (i) seu fim econômico ou social; (ii); a boa-fé; ou (iii) os bons costumes. Dessas três hipóteses, poder-se-ia aventar que o exercício do direito à indenização por danos evitáveis seria contrário à boa-fé.

No entanto, esse entendimento não parece razoável. A doutrina sobre o abuso do direito pressupõe a existência de uma situação jurídica ativa que possa ser exercida abusivamente. Obrigatoriamente, existe uma permissão jurídica, permissão esta da qual o agente se aproveita de maneira irregular. Porém, a mitigação de danos pressupõe o contrário: não existe permissão, mas sim, um dever do credor de mitigar seu prejuízo, de forma que sua inércia implica em uma sanção. Consequentemente, não é possível fundamentar a mitigação de danos no instituto do abuso de direito.

De mais a mais, a própria consequência jurídica do exercício abusivo do direito é contrária à mitigação de danos. No direito brasileiro, o abuso do direito configura ato ilícito (CCbr., art. 187). E, nos termos do art. 927 do CCbr., "aquele que, por ato ilícito (arts. 186 e 187), causar dano a outrem, fica obrigado a repará- lo". Nessa esteira, se a ausência de mitigação de danos fosse considerada abuso de direito, o credor se obrigaria a indenizar o devedor inadimplente. Contudo, a única consequência jurídica da ausência de mitigação de danos é a perda do direito do credor de ser indenizado pelos danos evitáveis. Assim, por mais essa razão, parece que a doutrina do abuso do direito não serve de fundamentação para a mitigação de danos no Brasil.

\subsection{Dever acessório}

Segundo o já mencionado Enunciado 169, o princípio da mitigação de danos representaria um dos deveres anexos à relação contratual entre as partes. O credor teria o dever de salvaguardar os interesses do devedor de forma a impedir que ele seja excessivamente onerado pela obrigação de indenizar (DIDIER JR., 2009). Tratar-se-ia de uma subespécie do dever lateral de cooperação que deriva da boa-fé objetiva (CCbr., art. 422).

Os deveres anexos estão relacionados a comportamentos positivos e recíprocos das partes contratantes com vistas a colaborar entre si para "o exato processamento da relação obrigacional, isto é, à satisfação dos interesses globais envolvidos, em atenção a uma identidade finalística, constituindo o complexo conteúdo da relação que se unifica funcionalmente" (MARTINS-COSTA, 2009, p. 440).

A noção de dever de cooperação se origina da ideia de que a relação obrigacional não se resume a prestações contrapostas, mas deve ser concebida como um processo de onde derivam direitos e deveres recíprocos. Nesse sentido, a boa-fé objetiva impõe às partes contratantes o cumprimento de um plexo de deveres secundários de conduta durante "o curso ou desenvolvimento de toda a relação jurídica" (COUTO E SILVA, 2006, p. 93).

Nessa esteira, a mitigação de danos no direito brasileiro assumiria feição de dever stricto sensu, obrigando o credor a cooperar com seu contratante, ainda que inadimplente, evitando que a obrigação do devedor de reparar o dano torne-se excessivamente onerosa. Assim, o comportamento do credor 


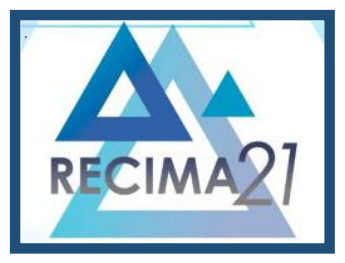

\section{RECIMA21 - REVISTA CIENTÍFICA MULTIDISCIPLINAR ISSN 2675-6218}

contrário à mitigação de danos consistiria em violação positiva do contrato, porque configuraria "inadimplemento, independentemente de culpa" (TARTUCE, 2018, p. 45). E, portanto, ensejaria a responsabilidade civil contratual do credor.

Não se concorda com esse entendimento. A concepção da mitigação de danos como dever, no sentido estrito do termo, pressupõe a existência de um direito subjetivo da outra parte. Nessa hipótese, o titular do direito subjetivo (devedor inadimplente) teria em suas mãos a possibilidade de buscar a execução específica da obrigação (dever de mitigar o próprio prejuízo) e a respectiva reparação em caso de descumprimento (PONTES DE MIRANDA, 1983). Melhor dizendo, se a mitigação de danos fosse concebida como um dever, o devedor poderia exigir judicialmente que o credor inadimplido cumprisse a obrigação de mitigar e o indenizasse por perdas e danos.

Contudo, não se tem conhecimento de um sistema jurídico que entende que o credor poderá ser constrangido a mitigar seu próprio prejuízo pelo devedor inadimplente, nem fica o credor obrigado a ressarcir o devedor por perdas e danos ao não evitar os efeitos nocivos da inexecução em seu patrimônio. $E$ faz todo sentido que assim o seja, porque a única consequência jurídica da ausência da mitigação de danos é a redução do montante indenizatório.

Diante disso, entende-se que não é possível conceber-se o princípio da mitigação como um dever acessório à relação contratual. Apesar disso, como será visto no próximo tópico, entende-se que o princípio da boa-fé objetiva deve servir como fundamento para recepcionar o princípio da mitigação de danos no direito brasileiro.

\subsection{1 Ônus}

Embora não seja juridicamente adequado entregar à mitigação de danos a natureza de dever, entende-se que o fundamento da mitigação no direito brasileiro deve residir na boa-fé objetiva (CCbr., art. 422). A corrente doutrinária que predomina defende que o princípio da boa-fé impõe ao credor um encargo ou ônus de mitigar seu próprio prejuízo, sob pena de serem excluídos de seu montante indenizatório os danos que era possível evitar. Essa é a natureza jurídica da mitigação de danos no direito brasileiro.

O ônus ou encargo tem a mesma estrutura de um dever. Contudo, possui características próprias: "[...] o encargo reflete a necessidade de uma conduta para aquisição ou conservação de uma determinada vantagem jurídica pelo agente, mas sem que a sua inobservância lese outra pessoa ou faça surgir qualquer obrigação de indenizar" (DIAS, 2011, p. 122).

Nesse sentido, enquanto o dever surge para albergar um interesse jurídico alheio, o ônus se refere à conservação de um interesse jurídico próprio, daí deriva a inexigibilidade do ônus. Especificamente, em se tratando da mitigação de danos, a boa-fé objetiva impõe ao credor o ônus de adotar determinado padrão de comportamento (reduzir e evitar os prejuízos decorrentes da inexecução do contrato) a fim de conservar seu direito à reparação integral das perdas causadas pelo devedor (CCbr., arts. 389, 402 e 422).

No direito brasileiro, o art. 771 do CC exemplifica o conceito de ônus. Esse dispositivo prevê que "sob pena de perder o direito à indenização, o segurado participará o sinistro ao segurador, logo RECIMA21 - Ciências Exatas e da Terra, Sociais, da Saúde, Humanas e Engenharia/Tecnologia 


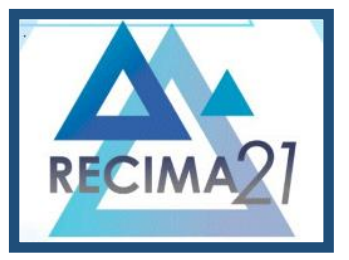

\section{RECIMA21 - REVISTA CIENTÍFICA MULTIDISCIPLINAR ISSN 2675-6218}

que o saiba, e tomará as providências imediatas para minorar-Ihe as consequências" (BRASIL, 2002, s.p.). Trata-se claramente de um encargo do segurado. Caso não informe o sinistro ao segurador, não será obrigado a arcar com perdas e danos, apenas perderá o benefício que a lei lhe assegura. Do mesmo modo, não pode o segurador coibir o segurado a Ihe informar o sinistro, exatamente por se tratar de um ônus.

Transportando a concepção de ônus ao inadimplemento contratual, tem-se que o credor possui o encargo de mitigar e evitar os danos que the são causados pela inexecução do devedor. Caso não observe "o encargo de afastamento do dano ou minimização de sua extensão, a vítima perderia, total ou parcialmente, o direito à indenização pelos respectivos danos que poderia ter evitado sofrer" (DIAS, 2011, p. 123). Essa é a natureza jurídica que a mitigação de danos deve ter no direito brasileiro.

A concepção da mitigação de danos como um ônus guarda correspondência com sua fundamentação jurídica na boa-fé objetiva. Entende-se que um dos efeitos da violação à boa-fé é justamente impedir que a parte se valha de um direito que estaria legitimada a exercer se tivesse agido de acordo com a boa-fé (LOPES, 2011). Trata-se do efeito corretivo da boa-fé, que impede o exercício de pretensões contrárias ao padrão de comportamento esperado do contratante de boa-fé.

\section{CONSIDERAÇÕES FINAIS}

Da análise do papel desempenhado pelos instrumentos de unificação e harmonização, concluise que o processo de aproximação jurídica promove o diálogo entre sistemas normativos em um esforço conjunto para o desenvolvimento do direito contratual de forma convergente. Como consequência desse processo, a evolução do direito contratual observa hoje um movimento cíclico em que diferentes sistemas interagem entre si. É nesse contexto que se desenvolve o princípio da mitigação de danos.

O estudo do direito estadunidense confirma a consagração no princípio da mitigação de danos no sistema anglo-saxão. É importante compreender o papel exercido pelo instituto nos EUA, porque, como analisado nesse trabalho, o sistema norte-americano teve influência fundamental na introdução do princípio da mitigação de danos no direito internacional público e na nova lex mercatoria.

Ressalte-se que nos EUA, a mitigação de danos não é concebida como um dever, mas sim, como uma limitação à indenização do credor inadimplido (Restatement [Second] of Contracts, § 350); as medidas adotadas pelo credor para mitigar seu prejuízo são auferidas pela noção de razoabilidade, parametrizada pelo curso normal dos negócios; os gastos despendidos pelo credor na adoção de medidas mitigatórias razoáveis são reembolsáveis pelo devedor; e o devedor tem o ônus de provar que o credor poderia ter mitigado seus prejuízos.

Referente ao desenvolvimento do princípio da mitigação de danos no ordenamento jurídico brasileiro, a CISG, também na qualidade de instrumento de soft law, tem sido a principal responsável pela recepção do princípio da mitigação de danos no direito brasileiro por meio da boa-fé objetiva (CCbr., art. 422). O sistema brasileiro, portanto, confirma a influência da interface entre sistemas normativos, impulsionada pelo processo de aproximação do direito contratual, sobre o desenvolvimento do princípio da mitigação de danos.

RECIMA21 - Ciências Exatas e da Terra, Sociais, da Saúde, Humanas e Engenharia/Tecnologia 


\section{RECIMA21 - REVISTA CIENTÍFICA MULTIDISCIPLINAR ISSN 2675-6218}

CONTRATOS INTERNACIONAIS PRIVADOS: BRASIL VERSUS ESTADOS UNIDOS DA AMÉRICA Gabriela Maia de Souza

\section{REFERÊNCIAS}

ALVIM, Agostinho Neves de Arruda. Da inexecução das obrigações e suas consequências. 4. ed. São Paulo: Saraiva, 1972.

BASSO, Maristela. Curso de direito internacional privado. 6. ed. São Paulo: Atlas, 2020.

BATES. Paul J. Mitigation of damages: a matter of commercial common sense. Advocate's Quarterly, v. 13, n. 3, p. 273-307, 1992.

CORDEIRO, Antonio Manuel da Rocha Menezes. Tratado de direito civil português: direito das obrigações: cumprimento e não cumprimento, transmissão, modificação e extinção, garantias. Coimbra: Almedina, 2010. v. 2, t. III.

COSTA, Mario Júlio Almeida. Direito das obrigações. 9. ed. Coimbra: Almedina, 2006.

COUTO E SILVA, Clóvis do. A obrigação como processo. Rio de Janeiro: FGV, 2006.

CRUZ, Gisela Sampaio da. O problema do nexo causal na responsabilidade civil. Rio de Janeiro: Renovar, 2005.

DIAS, Daniel Pires Novais. $O$ duty to mitigate the loss no direito brasileiro e o encargo de evitar o próprio dano. Revista de Direito Privado, v. 12, n. 45, p. 1-57, 2011.

DIDIER JR., Fredie. Multa coercitiva, boa-fé processual e supressio: aplicação do duty to mitigate the loss no processo civil. Revista Magister de Direito Civil e Processual Civil, v. VI, n. 32, p. 1-9, 2009.

DIREITO, Carlos Alberto Menezes. Comentários ao novo Código Civil. Rio de Janeiro: Forense, 2004. v. XIII.

FARNSWORTH, E. A. Legal remedies for breach of contract. Columbia Law Review, v. 70, n. 7, 1970.

GOETZ, Charles J.; SCOTT, Robert E. The mitigation principle: toward a general theory of contractual obligation. Virginia Law Review, 1983.

KULESZA, Gustavo Santos. Princípio da Mitigação de Danos. Curitiba: Juruá, 2015.

LOPES, Christian Sahb Batista. A mitigação dos prejuízos no direito contratual. Tese (Doutorado em Direito Civil) - Faculdade de Direito da Universidade Federal de Minas Gerais (UFMG), Minas Gerais, 2011.

MARTINS-COSTA, Judith. Comentários ao novo Código Civil: do inadimplemento das obrigações. Rio de Janeiro: Forense, 2009. v. 5, t. 2.

NALIN, Paulo; SIRENA, Hugo. A Convenção de Viena de 1980 e a sistemática contratual brasileira: a recepção principiológica do duty to mitigate the loss. Revista Jurídica, São Paulo, n. 422, p. 31-46, dez. 2012.

PEREIRA, Caio Mario da Silva. Instituições de Direito Civil. 33. ed. Rio de Janeiro:Forense, 2020. v. 1.

PONTES DE MIRANDA, Francisco. Tratado de Direito Civil. 3. ed. São Paulo: RT,1983. v. XXII.

TARTUCE, Flávio. Direito civil: teoria geral dos contratos e contratos em espécie. 14. ed. São Paulo: Método, 2018.

RECIMA21 - Ciências Exatas e da Terra, Sociais, da Saúde, Humanas e Engenharia/Tecnologia 


\section{RECIMA21 - REVISTA CIENTÍFICA MULTIDISCIPLINAR ISSN 2675-6218}

CONTRATOS INTERNACIONAIS PRIVADOS: BRASIL VERSUS ESTADOS UNIDOS DA AMÉRICA Gabriela Maia de Souza

TEPEDINO, Gustavo; SCHREIBER, Anderson. Código Civil Comentado: direitodas obrigações. São Paulo: Atlas, 2008. v. IV.

TREITEL, Guenter Heinz. Remedies for breach of contract: a comparativeaccount. Oxford: Claredon Press, 1991. 